\title{
Biological and Molecular Properties of a Begomovirus from Dicliptera sexangularis
}

\author{
Pongtharin Lotrakul, Rodrigo A. Valverde, and Angela D. Landry
}

Department of Plant Pathology and Crop Physiology, Louisiana Agricultural Experiment Station, Louisiana State University Agricultural Center, Baton Rouge 70803.

Accepted for publication 17 March 2000.

\begin{abstract}
Lotrakul, P., Valverde, R. A., and Landry, A. D. 2000. Biological and molecular properties of a begomovirus from Dicliptera sexangularis. Phytopathology: 90:723-729.

Sixangle foldwing, Dicliptera sexangularis (Acanthaceae), showing severe yellow mottle and leaf distortion symptoms was collected from the shoreline of Calusa Island (Lee County, FL). The putative virus was transmitted from infected $D$. sexangularis to healthy seedlings by mechanical, whitefly (Bemisia tabaci biotype B), and graft-inoculations. Different forms of geminivirus-like DNAs were detected in total DNA extracted from infected plants by Southern blot hybridization analyses using DNA-A and -B of Bean golden mosaic virus (BGMV) from Guatemala as probes. Preliminary polymerase chain reaction experiments and sequence comparisons indicated that the virus was a distinct bipartite begomovirus. The virus was designated Dicliptera yellow mottle virus

(DiYMV). Replicative dsDNAs of DiYMV were extracted, digested with selected restriction enzymes, and cloned into a plasmid vector. Both DNA-A and -B were sequenced and compared with those of other begomoviruses. Phylogenetic analyses using AV1, AC1, and BV1 nucleotide sequences indicated that DiYMV has a close relationship with the New World begomoviruses, especially those distributed in the nearby geographic areas of the Florida coast and the Caribbean Basin. However, different percent nucleotide sequence identities and phylogenetic relationships were detected when different open reading frames (ORFs) of DiYMV were compared with their counterparts from begomoviruses from the Caribbean Basin. Based on phylogenetic analyses of the AC1 and BV1 ORFs, DiYMV was closely related to BGMV type II isolates, whereas sequence comparisons of the common region and the AC4derived amino acid sequences indicated its close relationship with Potato yellow mosaic virus from Venezuela.
\end{abstract}

Members of the family Geminiviridae are a group of plant viruses that have small twin-isometric particles containing a single-stranded DNA genome (8). Geminiviruses can be classified into three genera based on their hosts, insect vector, and genome organization. Members of the genus Begomovirus are those that contain mono- or bipartite genomes, infect dicotyledonous plants, and can be transmitted by the whiteflies Bemisia tabaci and $B$. argentifolii. Viruses in the genus Mastrevirus infect mainly monocots, have monopartite genomes, and are transmitted by leafhoppers. Viruses in the genus Curtovirus infect a wide range of dicotyledonous plants, have monopartite genomes, and are transmitted by leafhoppers $(1,8)$.

Sixangle foldwing, Dicliptera sexangularis (L.) Juss. (Acanthaceae), is a perennial ornamental plant that ranges from South Florida to the West Indies. In 1998, plants showing bright yellow mottle and leaf distortion symptoms were collected from the shoreline of Calusa Island (Lee County, FL). Initial polymerase chain reaction (PCR) tests using degenerate primer pair AV494/AC1048, which amplifies the core region of the coat protein of many begomoviruses (14), yielded the expected DNA fragment $(550 \mathrm{bp})$, which suggested the presence of a begomovirus. This was confirmed by Southern blot hybridization analysis using a probe prepared with a full-length clone of DNAA of an isolate of Tomato yellow leaf curl virus (TYLCV-DR) from the Dominican Republic. Preliminary results indicated that the sequence of the begomovirus tested was distinct from those

Corresponding author: R. A. Valverde. E-mail address: rvalverde@agctr.lsu.edu

Nucleotide and/or amino acid sequence data have been submitted to the GenBank database as Accession nos. AF139168 and AF170101.

Publication no. P-2000-0509-02R

(C) 2000 The American Phytopathological Society published for other geminiviruses. Therefore, the purpose of this investigation was to further characterize this virus, designated Dicliptera yellow mottle virus (DiYMV), and to study its phylogenetic relationships with other begomoviruses.

\section{MATERIALS AND METHODS}

Sixangle foldwing plants were collected and maintained in a greenhouse. Healthy plants growing from seeds collected from symptomless plants were used for transmission experiments. A single virus isolate selected from preliminary individual whitefly transmission tests was used in all successive experiments.

Whitefly transmission. Colonies of the sweet potato whitefly (B. tabaci biotype B) were reared on caged cotton plants in the laboratory. Individual whiteflies and groups of 5, 10, and 20 were used for transmission experiments. Transmission experiments were conducted in the laboratory using DiYMV-infected $D$. sexangularis as the acquisition host and 3-week-old healthy seedlings as the test host. Whiteflies were caged with infected plants for $48 \mathrm{~h}$ and transferred to caged healthy plants for $48 \mathrm{~h}$. Test plants were sprayed with imidacloprid (Merit) and transferred to a greenhouse. Plants were evaluated for visual symptoms 2 to 3 weeks later. PCR or Southern blot hybridization using a Bean golden mosaic virus from Guatemala (BGMV-GA) DNA-A probe was performed with all test plants.

Host reaction. To determine the host range of DiYMV, three types of inoculations were conducted: mechanical, graft, and whitefly. In all cases, at least three plants of the same species were inoculated. Mechanical inoculations were conducted by grinding tissues in $0.02 \mathrm{M}$ phosphate buffer $(\mathrm{pH}$ 7.2) and rubbing the inoculum on Carborundum-dusted leaves. The following plant species were inoculated: D. sexangularis, Nicotiana benthamiana, N. clevelandii, Chenopodium quinoa, Cucumis sativus, 
Gomphrena globosa, Ipomoea nil cv. Scarlett O'Hara, and Phaseolus vulgaris cv. Pinto. Graft inoculations were conducted using infected $N$. benthamiana as the source of scions to inoculate Datura stramonium, Capsicum annuum cv. Yolo Wonder, C. frutescens cv. Tabasco, Lycopersicon esculentum cvs. Better Boy and Rutgers, $N$. benthamiana, and Solanum melongena cv. Ichiban. Infected $D$. sexangularis was used as the source of scions to graft-inoculate the following family Acanthaceae members: D. sexangularis, Justicia carnea, J. brandegiana, Hypoestes sp., and Ruellia sp. Groups of 50 whiteflies were used to inoculate Brassica oleraceae var. capitata, C. annuиm cv. Yolo Wonder, Fittonia sp., Glycine max cv. Williams, Gomphrena globosa, I. nil cv. Scarlet O'Hara, L. esculentum cv. Better Boy, P. vulgaris cv. Pinto, Physalis floridana, Solanum tuberosum, and Vigna unguiculata cv. Blackeye. All test plants were examined for symptoms 2 to 3 weeks after inoculations. PCR was performed on all plant species tested.

DNA extraction and Southern blot hybridization analyses. Total DNA from infected $D$. sexangularis foliar tissue was extracted either by a protocol described by Dellaporta et al. (4) or using plant DNAzol reagent (Life Technologies Inc., Grand Island, NY). Extracted DNA was separated by electrophoresis and stained with ethidium bromide. Southern hybridization was conducted using an ECL kit (Amersham Corp., Arlington Heights, IL) following the manufacturer's procedures. TYLCV-DR and BGMV-GA were used as specific probes. The hybridization was carried out under conditions previously described (11). The DNAA of the Dicliptera-infecting geminivirus was amplified by PCR using universal primers designed by Briddon and Markham (2). A partial sequence of the genome where the primers bound was obtained using an additional pair of primers designed from the sequence of the previously obtained PCR fragment. A 1-kb DNAB fragment was amplified with primer pair PrBV1855/PrBC656 (9). PCR was performed in an Amplitron II thermocycler (Thermolyne, Dubuque, IA) as previously described (10). The PCR products were recovered from agarose gels using the Ultraclean15 DNA purification kit (MO Bio Laboratories Inc., Solana Beach, CA). Purified PCR products were cloned into pBluescript II SK(+) (Stratagene, La Jolla, CA). Taq DNA polymerase, restriction endonucleases, and T4 DNA ligase were used as recommended by the manufacturers. Recombinant plasmids were then transformed into competent cells of Escherichia coli strain DH5 $\alpha$.

Cloning of the viral genome. The replicative form (RF) of the begomovirus genome was isolated from infected tissue as described previously by Gilbertson et al. (6). Based on sequences obtained from PCR-amplified fragments using universal primers (2), selected restriction enzymes were chosen for cloning the

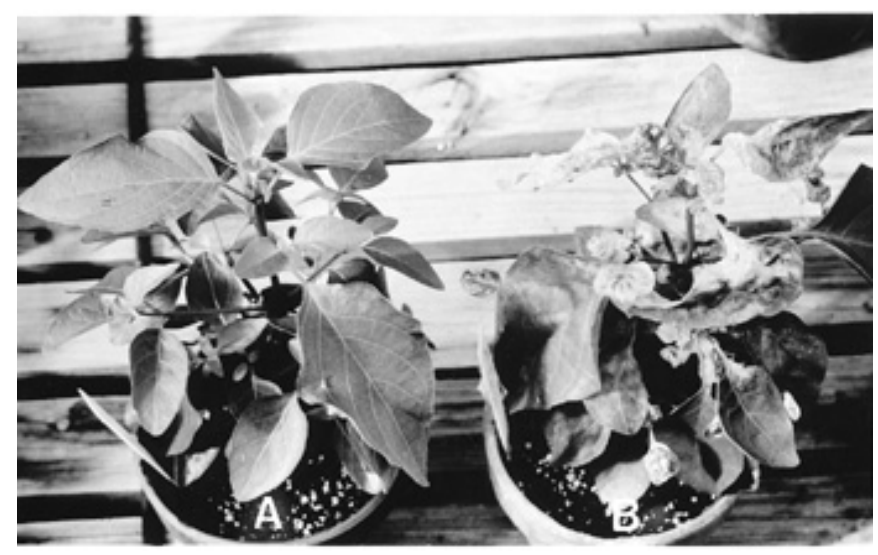

Fig. 1. A and B, Healthy Dicliptera sexangularis and D. sexangularis infected with Dicliptera yellow mottle virus, showing leaf distortion and yellow mottle symptoms. complete viral genome. The plasmid pBluescript II SK(+) was used as the vector. Recombinant plasmids containing the putative full-length DNA-A of DiYMV were screened by Southern blot hybridization with BGMV-GA DNA-A; those containing putative full-length DNA-B inserts were screened by hybridizations with BGMV-GA DNA-B.

Infectivity of cloned DiYMV DNA. For these experiments, the cloned inserts of DiYMV DNA-A and -B were excised from the plasmid vector by digestion with BamHI and ApaI, respectively. The DNA of each genomic component was purified using the Ultraclean15 DNA purification kit after electrophoresis and then ligated with T4 DNA ligase to form closed circular dsDNA. After quantitation by the ethidium bromide fluorescent method, the ligated DNA in the reaction mixture was diluted in $0.1 \mathrm{M}$ sodium phosphate buffer ( $\mathrm{pH} 7.0$ ). Approximately $0.3 \mu \mathrm{g}$ of each genomic component was mechanically inoculated onto Carborundumdusted primary leaves and cotyledons of 2-week-old $D$. sexangularis. Four groups of three plants each were inoculated. The first was mock inoculated with phosphate buffer, the second with DNA-A, the third with DNA-B, and the fourth with both DNA-A and -B. Two independent experiments were conducted. Inoculated plants were kept in the greenhouse and examined for symptoms 10 to 14 days after inoculation. PCR was performed using universal primers for begomoviruses (2) and primer pair PrBV1855/PrBC656 (9) with DNA extracts from all inoculated plants.

Sequence determination. Nucleotide sequences were determined by automated sequence analysis at the DNA Sequencing Core Laboratory, University of Florida, Gainesville (ABI337 DNA Sequencer; Perkin Elmer, Foster City, CA). At least three replicate PCR clones were sequenced to minimize errors caused by $T a q$ polymerase. For the full-length clones obtained from the replicative DNA, two-direction sequencing was performed. Open reading frames (ORFs) and predicted amino acid sequences were determined using the TRANSLATE program (ExPASy Molecular Biology Server, Swiss Institute of Bioinformatics, Geneva, Switzerland).

Sequence comparisons and phylogenetic analyses. The obtained nucleotide and derived amino acid sequences were compared with those of other begomoviruses. Multiple sequence alignment was carried out using version 1.7 of the CLUSTAL W program (13). Percent identities and similarities between aligned nucleotide and derived amino acid sequences were determined by $[100 \times$ sum of matching residues/(length - gap residues (sequence 1) - gap residues (sequence 2))] (3). Phylogenetic analyses using parsimony and bootstrap options (100 replicates) were performed using version 3.5c of the Phylogeny Inference Package (PHYLIP) developed and distributed by J. Felsenstein (Department of Genetics, University of Washington, Seattle). Bootstrap values were shown using the $>60 \%$ majority rule. Geminivirus sequences used in sequence and phylogenetic analyses are listed in the GenBank database under the following accession numbers: Abutilon mosaic virus (AbMV; X15983, X15984), African cassava mosaic virus from Nigeria (ACMV-NG; X17095), Ageratum yellow vein virus (AYVV; X74516), Bean dwarf mosaic virus (BDMV; M88179, M88180), Bean calico mosaic virus (BCMoV; AF110189, AF110190), BGMV from Brazil (BGMVBZ; M88686, M88687), BGMV from the Dominican Republic (BGMV-DR; L01635, L01636), BGMV from Guatemala (BGMVGA; M91604, M91605), BGMV from Puerto Rico (BGMV-PR; M10070, M10080), Beet curly top virus (BCTV; U56975), Cabbage leaf curl virus (CaLCV; U65529, U65530), Chayote mosaic virus (CMoV; AJ223191), Cotton leaf curl virus from Pakistan (CLCuV; AJ002448, AJ002449), Cowpea golden mosaic virus (CPGMV; AF029217), Havana tomato virus (HTV; Y14874, Y14875), Indian cassava mosaic virus (ICMV; Z24758, $\mathrm{Z} 24759)$, Ipomoea yellow vein virus (IYVV; AJ132548), Mungbean yellow mosaic virus (MYMV; AB017341, D14704), 
Okra yellow vein mosaic virus (OYVMV; AJ002451), Papaya leaf curl virus (PLCV; Y15934), Pepper huasteco virus (PHV; X70418, NC001369), Potato yellow mosaic virus from Trinidad and Tobago (PYMV-TT; AF039031, AF039032), PYMV from Venezuela (PYMV-VE; D00940, D00941), Sida golden mosaic virus from Florida (SiGMV-FL; AF049336, AF039841), Squash leaf curl virus isolate E (SLCV-E; M38183, M38182), Sweet potato leaf curl virus from the United States (SPLCV-US; AF104036), Taino tomato mottle virus (TToMV; AF012300, AF012301), Texas pepper virus from Costa Rica (TPV-CR; AF149227), TPV from Tamaulipas (TPV-TAM; U57457), Tomato leaf crumple virus (TLCrV; AF101476, AF101478), Tomato leaf curl virus from Taiwan (ToLCV-TW; U88692), Tomato mottle virus (ToMoV; L14460, L14461), TYLCV from Israel (TYLCVIS; X15656), and TYLCV from Spain (TYLCV-SP; Z25751).

\section{RESULTS}

Host reaction and whitefly transmission. Leaf distortion and yellow mottle symptoms appeared on D. sexangularis (Fig. 1) approximately 2 wks after either sap- or graft-inoculation or exposure to whiteflies that fed on infected plants. The sweet potato whitefly (B. tabaci biotype B) transmitted DiYMV to $D$. sexangularis at a relatively high rate (Table 1). The virus was not detected in all symptomless plants by PCR or Southern hybridization. $N$. benthamiana was infected with DiYMV by sapand graft-inoculation. $N$. clevelandii was infected by sapinoculations, and D. stramonium was infected by graft- and whitefly-inoculation. Leaf curl symptoms developed on infected $N$. benthamiana and $N$. clevelandii 8 to 10 days after inoculations. Although D. stramonium remained symptomless, PCR ampli-

TABLE 1. Sweet potato whitefly (Bemisia tabaci biotype B) transmission of Dicliptera yellow mottle virus to individual Dicliptera sexangularis plants after 2-day acquisition and transmission feeding periods ${ }^{\mathrm{a}}$

\begin{tabular}{lccc}
\hline Whiteflies/plant & Experiment 1 & Experiment 2 & Experiment 3 \\
\hline 1 & $1 / 5^{\mathrm{b}}$ & $2 / 6$ & $1 / 7$ \\
5 & $6 / 7$ & $5 / 6$ & $\ldots$ \\
10 & $9 / 10$ & $8 / 15$ & $13 / 15$ \\
20 & $5 / 7$ & $13 / 15$ & $\ldots$ \\
\hline
\end{tabular}

a Acquisition and transmission host was $D$. sexangularis.

${ }^{b}$ Number of infected plants per number of plants tested. fication using specific primers (AV494/AC1048) (14) indicated the presence of DiYMV in inoculated plants (data not shown). Attempts to transmit DiYMV to all other plant species failed.

Detection of DiYMV DNA by Southern blot hybridization. DNA probes consisting of either BGMV-GA DNA-A or -B hybridized with three DNA bands $(\approx 2.0,2.6$, and $4.0 \mathrm{~kb}$, respectively) that were present on Southern blots of total DNAs extracted from plants infected with DiYMV (data not shown). These bands represented three forms of the DiYMV genome: covalently closed circular, single-stranded, and open circular forms, respectively. Similar results were obtained when either DNA-A or -B of the BGMV-GA probe was used, suggesting the bipartite nature of DiYMV.

Cloning of the DiYMV genome. Full-length clones of DiYMV DNA-A and -B were obtained by cloning RF DNA into a plasmid vector. DNA-A of the virus was digested with BamHI, whereas DNA-B was digested with $A p a \mathrm{I}$ restriction enzyme prior to being cloned into BamHI- and ApaI- digested pBluescript II, respectively. In both cases, several recombinant plasmids containing a 2.6-kb insert were obtained. These inserts hybridized with either the BGMV-GA DNA-A or -B probes, suggesting that both DiYMV genomic components were cloned. The restriction

TABLE 2. Percent nucleotide identity of Dicliptera yellow mottle virus DNA-A and -B with those of other begomoviruses from the New World

\begin{tabular}{lcc}
\hline Virus & DNA-A & DNA-B \\
\hline Abutilon mosaic virus & 76.1 & 68.5 \\
Bean calico mosaic virus & 71.8 & 69.2 \\
Bean dwarf mosaic virus & 75.6 & 70.4 \\
Bean golden mosaic virus (BGMV)-Brazil & 74.4 & 68.9 \\
BGMV-Dominican Republic & 75.8 & 73.9 \\
BGMV-Guatemala & 77.3 & 72.0 \\
BGMV-Puerto Rico & 76.7 & 71.2 \\
Cabbage leaf curl virus & 73.7 & 69.7 \\
Havana tomato virus & 76.3 & 68.6 \\
Pepper huasteco virus & 72.7 & 67.6 \\
Potato yellow mosaic virus (PYMV)-Trinidad and Tobago & 76.4 & 68.9 \\
PYMV-Venezuela & 76.1 & 68.7 \\
Sida golden mosaic virus -Florida & 77.0 & 68.2 \\
Squash leaf curl virus isolate E & 69.9 & 65.9 \\
Texas pepper virus (TPV)-Costa Rica & 70.6 & NA \\
TPV-Tamaulipas & 71.1 & NA \\
\hline
\end{tabular}

${ }^{\mathrm{a}} \mathrm{NA}=$ not available
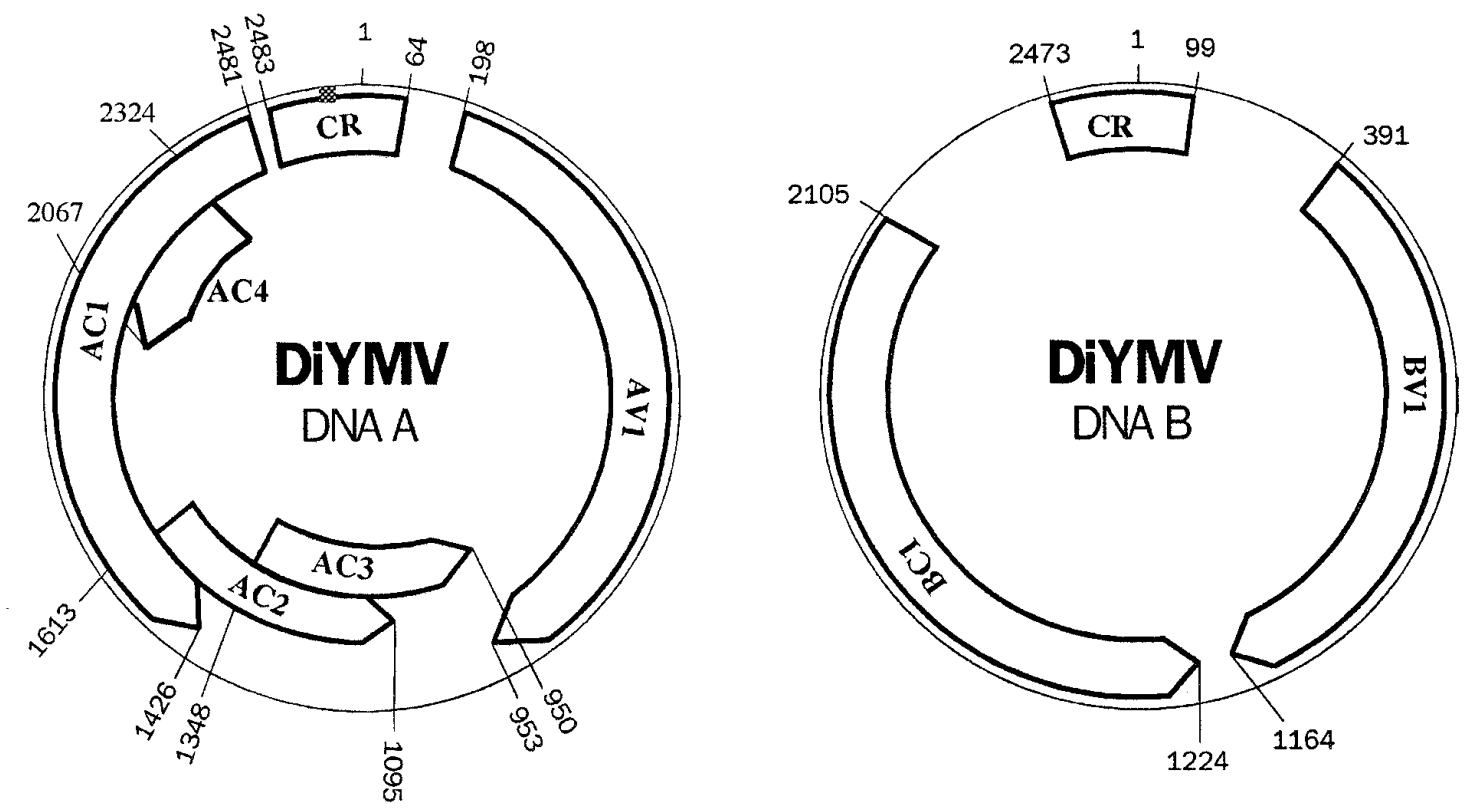

Fig. 2. Genome organization of Dicliptera yellow mottle virus (DiYMV) DNA-A and -B. Arrows represent the orientation of the open reading frames. Numbers represent the position of nucleotides on the genome. 
map analysis of both DNA inserts was carried out using selected restriction enzymes based on sequence information obtained from PCR clones.

Infectivity of cloned DiYMV DNA. Ten days after inoculation, $67 \%$ of $D$. sexangularis seedlings inoculated with the mixture of DNA-A and -B showed yellow mottle and leaf distortion symptoms, and both DNAs were detected by PCR. Plants inoculated with only DNA-A or -B did not develop symptoms, and viral DNA was not detected by PCR in newly emerged leaves.

Genome organization. The complete nucleotide sequence of DiYMV DNA-A contained 2,607 bp (GenBank Accession no: AF139168), and the DNA-B sequence contained 2,597 bp (GenBank Accession no: AF170101). Computer-assisted analysis revealed seven ORFs: five on DNA-A (AV1, AC1, AC2, AC3, and $\mathrm{AC} 4$ ) and two on DNA-B (BV1 and BC1), which is typical of a bipartite begomovirus. ORFs were located on both virion and complementary sense strands. The genome organization of DiYMV DNA-A and -B are shown in Figure 2. Based on restriction map analysis of the full-length clones, there was a variation in the DNA-B sequence. At least two different sequences were detected, one with two BglII sites (nucleotides 1804 and 2221) and the other with only one BglII site (nucleotide 1804) (data not shown). PCR amplification and analysis of seven independent clones suggested that DNA-B with two BglII sites was the most common (data not shown).

The nucleotide sequences of DNA-A and -B of DiYMV showed little sequence identity, except a nearly identical common region with $93.6 \%$ identity (189 nucleotides (nt) on DNA-A and $191 \mathrm{nt}$ on DNA-B). Comparisons between both DNA-A and -B of DiYMV and those of other begomoviruses indicated that DiYMV is a distinct bipartite begomovirus species (Table 2). Higher percent nucleotide identities were detected with begomoviruses from the New World than with those from the Old World (data not shown). Among the New World species, nucleotide sequence identity ranged from 69.9 to $77.3 \%$ for DNA-A and from less than 65.9 to $73.9 \%$ for DNA-B (Table 2). Higher percent identity was detected between DiYMV and begomoviruses from the Caribbean Basin than among those from the inland areas of the United States, such as the E strain of SLCV from California and TPV isolates (Table 2).

Nucleotide and derived amino acid sequence comparisons between DiYMV ORFs and equivalent ORFs of eight begomoviruses from Florida and the Caribbean Basin were made (Table 3). SLCV-E was also included in these comparisons because of the relatively high nucleotide sequence identity with DiYMV detected in preliminary sequence comparisons. Of all seven ORFs, AV1 was the most conserved, with up to 84 and $92 \%$ nucleotide and derived amino acid sequence identity, respectively (Table 3). Based on the AV1 ORF, there was only a slight difference in percent identity among all nine viruses compared, and the highest value was detected with BGMV-GA (Table 3). In the case of the AC1 ORF, the highest percent derived amino acid identity (80\%) was detected with that of PYMV-TT, and the lowest was detected with CaLCV and SLCV-E (64.3 and 65.2\%, respectively). In contrast, CaLCV was the most similar to DiYMV when the AC2 and AC3 sequences were compared, and those of SLCV-E were the most different (Table 3). Based on the AC4derived amino acid sequence, the highest percent identity $(64.7 \%)$ was detected between DiYMV and PYMV from Venezuela. In the case of ORFs on the DNA-B, BC1 was more conserved than BV1 with percent derived amino acid identity of up to $85 \%$. Less than $76 \%$ amino acid identity was detected when the DiYMV BV1 sequence was compared with those of other New World begomoviruses (Table 3). Both DNA-B ORFs of DiYMV showed the highest percent derived amino acid identity with those of BGMV-DR and the lowest with those of SLCV-E and HTV (Table 3).

The sequence and organization of the iterative elements located on the common region were also investigated. Two iterative elements (TTCCCCCAG/A and C/TTGGGGGAA), each with two nearly identical copies, were detected on the $5^{\prime}$ end of the common region related to the conserved stem-loop motif (Fig. 3). When they were aligned, these iterative elements found in the DiYMV common region were almost identical to those of PYMVVE (Fig. 3).

Phylogenetic analyses. Relationships between DiYMV and other whitefly-transmitted geminiviruses were analyzed based on the AV1, AC1, and BV1 nucleotide sequences. All ORFs analyzed indicated a close relationship between DiYMV and the New World begomoviruses. The position of DiYMV on the parsimony tree based on the AV1 sequence was distinct but still clustered with begomoviruses from the New World (Fig. 4A). When its relationship with other begomoviruses was analyzed based on the AC1 sequence, DiYMV was clustered with the type II isolates of BGMV from Guatemala, the Dominican Republic, and Puerto Rico (Fig. 4B). Its relationship with other New World begomoviruses was further investigated by comparing the BV1 ORF. Again, DiYMV was clustered with the type II BGMV isolates (Fig. 4C).

\section{DISCUSSION}

The biological and molecular characteristics of DiYMV and its phylogenetic relationships with other begomoviruses indicate that DiYMV is a novel bipartite begomovirus species. Cloned DiYMV DNAs used to generate the sequence data represent the genome of the etiologic agent causing disease on $D$. sexangularis. This is supported by the results of mechanical inoculations of $D$. sexangularis with the cloned DNA. Symptoms that resulted from these inoculations were similar to those induced by the original whitefly-transmitted isolate. DiYMV was transmitted at a relatively high rate by $B$. tabaci biotype B. DiYMV appears to have a narrow host range. Surprisingly, none of the other four tested species within the family Acanthaceae was susceptible.

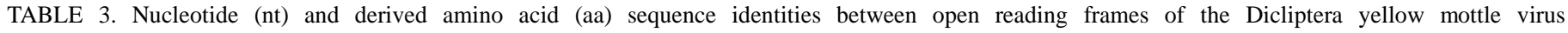
and those of begomoviruses from Florida and the Caribbean Basin

\begin{tabular}{|c|c|c|c|c|c|c|c|}
\hline \multirow[b]{2}{*}{ Virus } & \multicolumn{7}{|c|}{ Percent Identity (nt/aa) } \\
\hline & AV1 & $\mathrm{AC} 1$ & $\mathrm{AC} 2$ & $\mathrm{AC} 3$ & $\mathrm{AC} 4$ & BV1 & $\mathrm{BC} 1$ \\
\hline \multicolumn{8}{|l|}{ Bean golden mosaic virus } \\
\hline BGMV-Dominican Republic & $82.9 / 91.2$ & $75.8 / 78.9$ & $77.8 / 61.6$ & $74.9 / 69.7$ & $80.2 / 50.6$ & $77.0 / 75.4$ & $79.6 / 85.3$ \\
\hline BGMV-Guatemala & $83.7 / 92.4$ & $75.2 / 77.5$ & $78.0 / 62.2$ & $75.7 / 70.5$ & $81.0 / 50.6$ & $75.9 / 73.1$ & $79.0 / 85.0$ \\
\hline BGMV-Puerto Rico & $82.8 / 89.6$ & $74.2 / 76.1$ & $78.0 / 61.1$ & $75.7 / 69.7$ & $81.0 / 51.8$ & $76.4 / 74.6$ & $79.1 / 84.3$ \\
\hline Cabbage leaf curl virus & $84.4 / 89.2$ & $65.3 / 64.3$ & $76.7 / 66.9$ & $79.5 / 70.5$ & $61.7 / 23.5$ & $74.6 / 72.3$ & $78.4 / 82.9$ \\
\hline Havana tomato virus & $81.0 / 88.1$ & $78.2 / 79.0$ & $74.9 / 60.6$ & $75.2 / 67.4$ & $80.2 / 56.5$ & $71.4 / 69.0$ & $76.9 / 74.1$ \\
\hline \multicolumn{8}{|l|}{ Potato yellow mosaic virus } \\
\hline (PYMV)-Trinidad and Tobago & $79.1 / 87.3$ & $77.4 / 80.0$ & $74.9 / 64.6$ & $76.2 / 68.2$ & $81.4 / 58.8$ & $68.6 / 68.0$ & $77.6 / 82.6$ \\
\hline PYMV-Venezuela & $80.2 / 87.7$ & $75.5 / 78.4$ & $74.9 / 65.1$ & $74.4 / 68.9$ & $81.4 / 64.7$ & $68.6 / 68.0$ & $76.6 / 81.2$ \\
\hline Squash leaf curl virus isolate $\mathrm{E}$ & $82.3 / 90.0$ & $66.8 / 65.2$ & $73.2 / 61.4$ & $72.7 / 65.9$ & $56.4 / 21.2$ & $65.5 / 62.1$ & $72.1 / 79.9$ \\
\hline
\end{tabular}


Currently, the natural host range and distribution of DiYMV is unknown. The natural range of $D$. sexangularis lies from the West Indies through central and southern Florida, including the Keys. This plant is a perennial ornamental that is easily grown and can be propagated vegetatively or through seeds.

There was a variation in symptoms of naturally infected $D$. sexangularis. Although the majority of infected plants showed bright yellow mottle and severe leaf distortion symptoms, a few plants showed only severe leaf distortion (data not shown). The variation in symptoms might be the result of a variation in DiYMV DNA-B sequences. In this study, we used the cloned DNA-B of DiYMV that has two BglII sites (submitted sequence to GenBank) for inoculation of $D$. sexangularis seedlings. Plants inoculated with both DNA-A and -B developed bright yellow mottle and severe leaf distortion symptoms similar to those of naturally infected plants. However, additional experiments using the cloned DiYMV DNA-B with one BglII site (not sequenced) resulted in plants showing only severe leaf distortion symptoms (data not shown). Further analyses and sequence comparisons of DiYMV DNA-B might reveal the cause of this symptom variation.

DiYMV likely originated in the New World. Based on the sequences of the AV1 and AC1 ORFs and the iterative elements located in the common region, several researchers have proposed that the New World begomoviruses consist of several clusters $(1,5)$. According to the study conducted by Faria and coworkers (5), the New World begomoviruses may be classified into seven cluster groups: AbMV, BGMV type I, BGMV type II, PHV, PYMV-VE, SLCV, and Tomato golden mosaic virus (TGMV). Based on nucleotide and derived amino acid sequence identity, DiYMV seems to be more closely related to begomoviruses distributed in the nearby geographic areas of Florida and the Caribbean Basin where its natural host, D. sexangularis, also is present. This is supported by the results of phylogenetic analyses.
Analyses of the AC1 and BV1 sequences clearly indicated a close relationship between DiYMV and the type II isolates of BGMV. However, based on sequence comparisons of the common region and the derived AC4 amino acid sequence, it seems that DiYMV is also related to another group of the New World begomoviruses, PYMV-VE. This raises the possibility that DiYMV might have originated from recombination(s) among common ancestors of the New World begomoviruses, especially those distributed in the Caribbean Basin. The alternative possibility is that DiYMV might have evolved and then diverged away from a PYMV-like virus. Furthermore, because DiYMV contains iterative element sequences and arrangements nearly identical to those of PYMV$\mathrm{VE}$, it is possible that transreplication between these two viruses may occur. The iterative elements have been suggested to play an important role in the virus replication as the binding site of the replication-associated (Rep) protein (1). Although the DiYMV Rep protein shares only $78 \%$ derived amino acid sequence identity (94\% similarity) to that of PYMV-VE, it is still possible that the DiYMV Rep protein might recognize and bind PYMV-VE iterative elements and vice versa. Pseudorecombination between two begomoviruses, BDMV and ToMoV, that share only $83 \%$ Rep protein amino acid identity (91\% similarity), was clearly demonstrated by Gilbertson et al. (7). However, to prove this possibility, pseudorecombination experiments need to be conducted.

\section{ACKNOWLEDGMENTS}

We wish to thank R. Johnson, Sakata Seed America of Ft. Myers, FL, and the Calusa Land Trust and Nature Preserve of Pine Island, FL, for access to the island and R. Wunderlin, Department of Biology, University of South Florida, for identification of $D$. sexangularis and R. Gilbertson for providing clones of TYLCV-DR and BGMV-GA. Approved for publication by the director, Louisiana Agricultural Experiment Station, manuscript 99-38-0345.

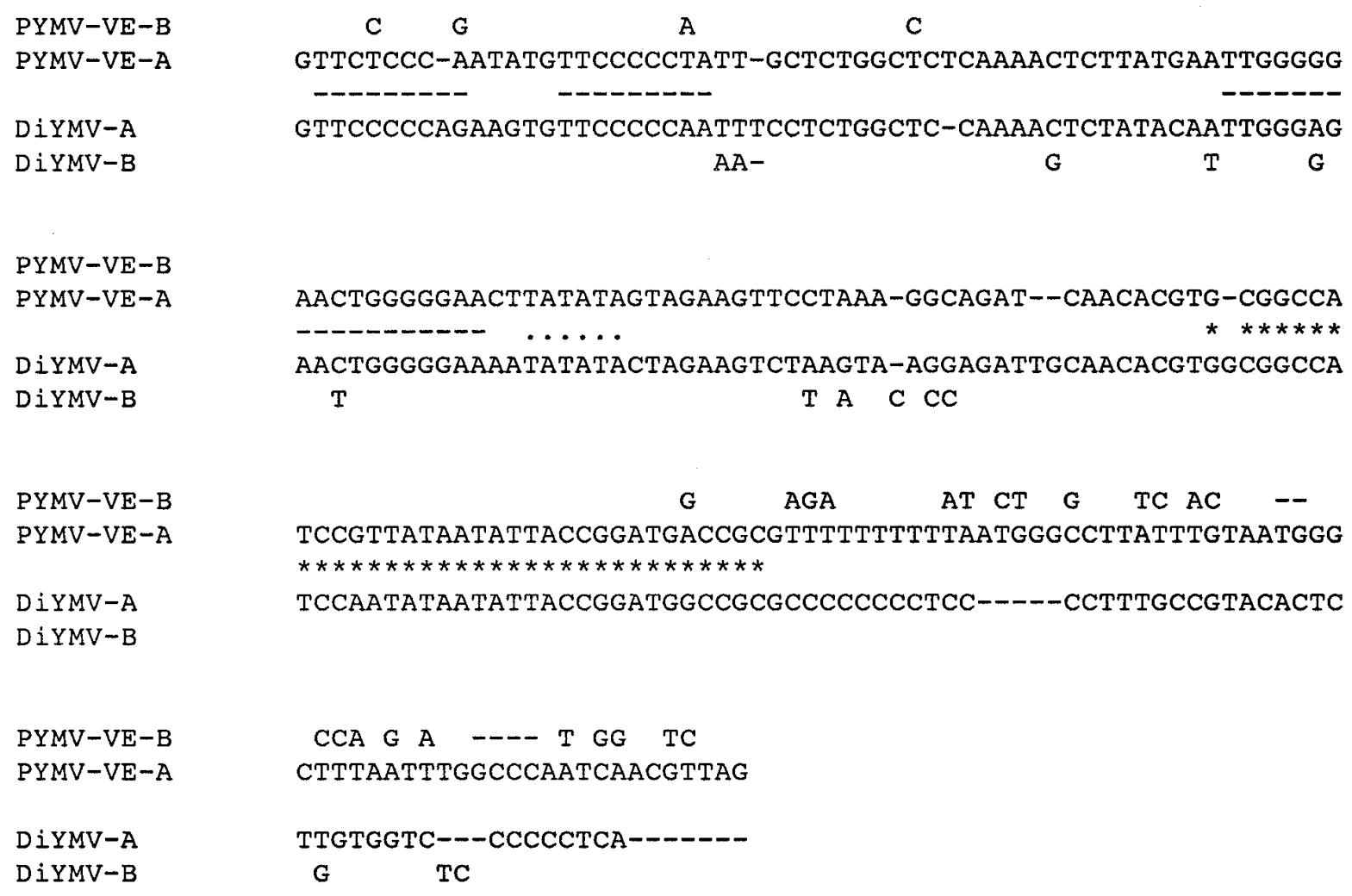

Fig. 3. Sequence alignment of the common region of Potato yellow mosaic virus from Venezuela (PYMV-VE) and Dicliptera yellow mottle virus (DiYMV). Underlined bases represent the iterative elements. Bases marked with a dot represent the TATA box, and bases marked with an asterisk represent the conserved stem-loop motif. Bases above and under the aligned sequences represent variation in the common region. 
$\mathbf{A}$

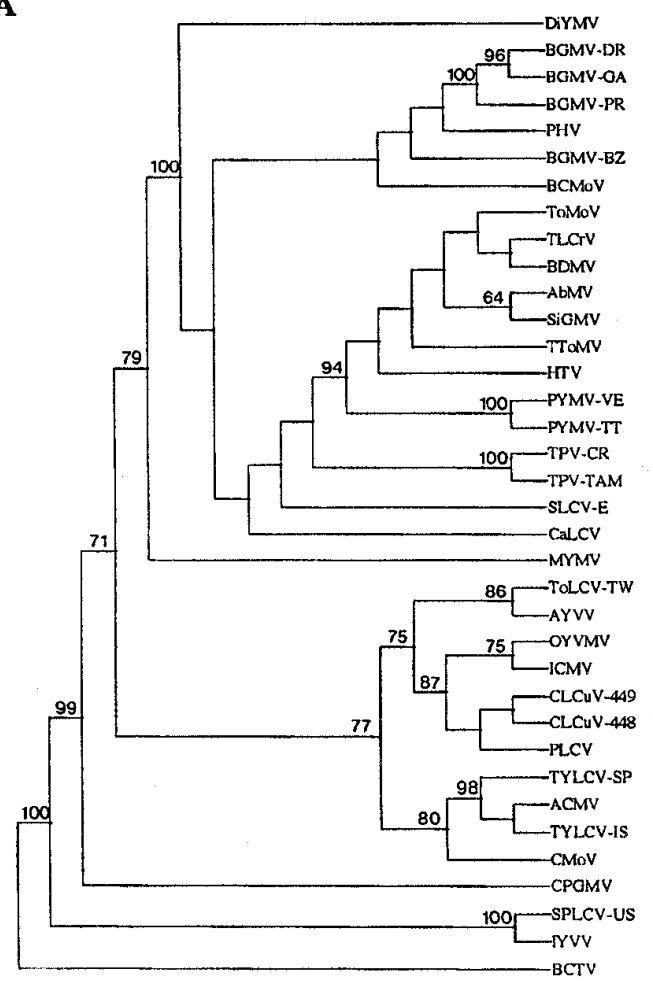

B

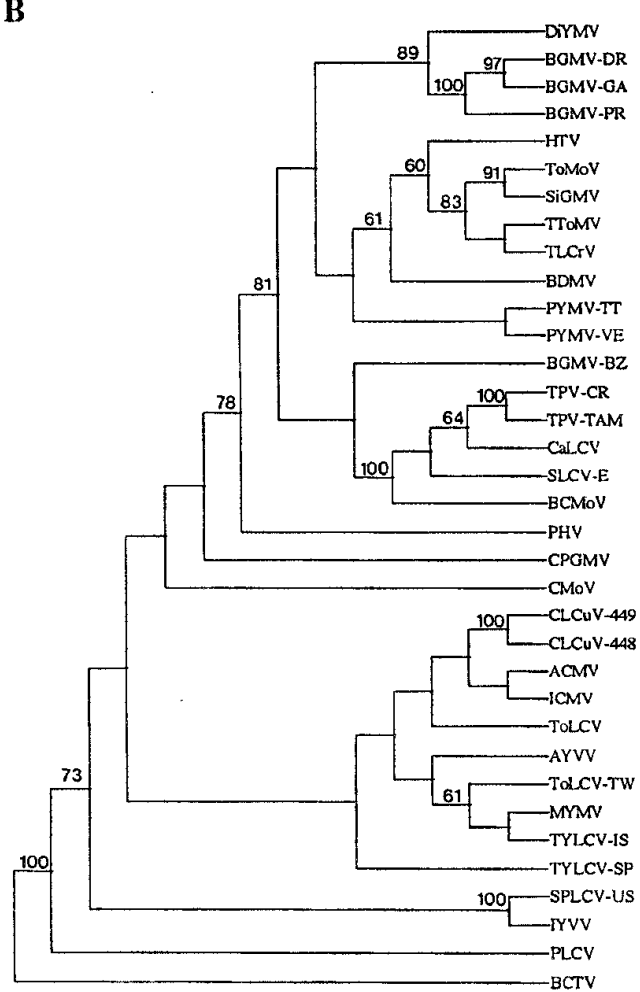

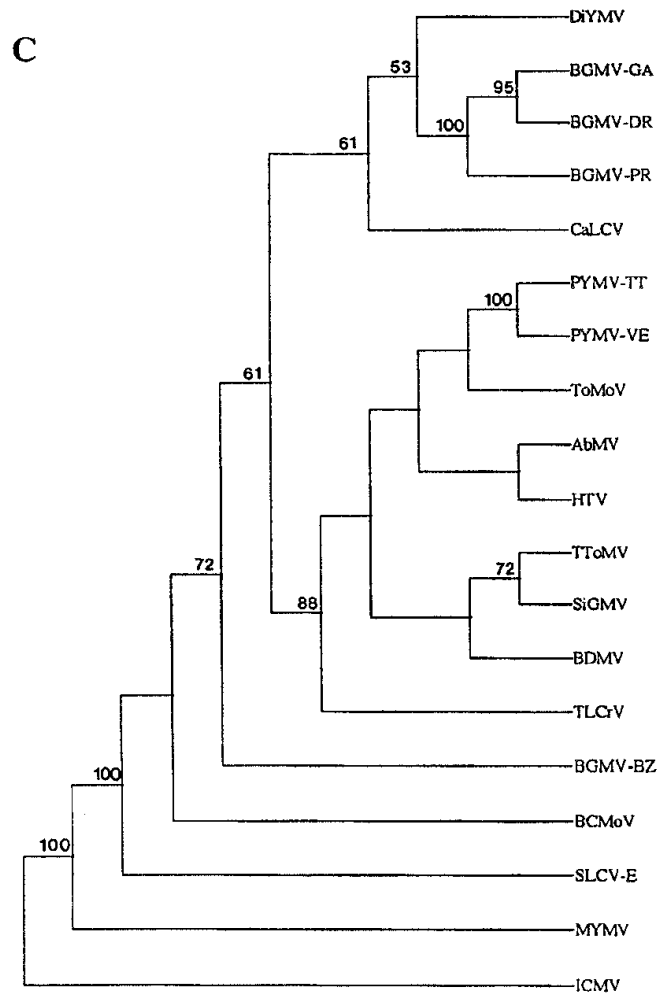

Fig. 4. Phylogenetic tree of the relationship of Dicliptera yellow mottle virus (DiYMV) with other begomoviruses based on the multiple alignment of A, AV1; B, AC1; and C, BV1 nucleotide sequences using programs in the CLUSTAL W package, version 1.7. Trees were constructed using SEQBOOT, DNAPARS, and CONSENSE programs in PHYLIP package version 3.5c. Analysis of 100 trees constructed resulted in only one most parsimonious tree. On each internal branch, the bootstrap number is shown with $60 \%$ majority rule. Vertical and horizontal branch lengths are arbitrary. Beet curly top virus (BCTV), a curtovirus, was used as an outgroup. Selected viruses include: Bean golden mosaic virus (BGMV)-Dominican Republic (DR), Guatemala (GA), Puerto Rico (PR), and Brazil (BZ); Pepper huasteco virus (PHV); Bean calico mosaic virus (BCMoV); Tomato mottle virus (ToMoV); Tomato leaf crumple virus (TLCrV); Bean dwarf mosaic virus (BDMV); Abutilon mosaic virus (AbMV); Sida golden mosaic virus (SiGMV); Taino tomato mottle virus (TToMV), Havana tomato virus (HTV); Potato yellow mosaic virus (PYMV)-Venezuela (VE), and Trinidad and Tobago (TT); Texas pepper virus (TPV)-Costa Rica (CR), and Tamaulipas (TAM); Squash leaf curl virus, isolate E (SLCV-E); Cabbage leaf curl virus (CaLCV); Mungbean yellow mosaic virus (MYMV); Tomato leaf curl virus (ToLCV)-Taiwan (TW); Ageratum yellow vein virus (AYVV); Okra yellow vein mosaic virus (OYVMV); Indian cassava mosaic virus (ICMV); two strains of Cotton leaf curl virus (CLCuV) 449/448; Papaya leaf curl virus (PLCV); Tomato yellow leaf curl virus (TYLCV)-Spain (SP), African cassava mosaic virus (ACMV); TYLCV-Israel (IS); Chayote mosaic virus (CMoV); Cowpea golden mosaic virus (CPGMV); Sweet potato leaf curl virus (SPLCV)-United States (US); and Ipomoea yellow vein virus (IYVV). 


\section{LITERATURE CITED}

1. Arguello-Astorga, G. A., Guevara-Gonzales, R. G., Herrera-Estrella, L. R., and Rivera-Bustamante, R. F. 1994. Geminivirus replication origins have a group-specific organization of iterative elements: A model for replication. Virology 203:90-100.

2. Briddon, R. W., and Markham, P. G. 1994. Universal primers for the PCR amplification of dicot-infecting geminiviruses. Mol. Biotechnol. 1:202-205.

3. Brown, J. K., Ostrow, K. M., Idris, A. M., and Stenger, D. C. 1999. Biotic, molecular, and phylogenetic characterization of bean calico mosaic virus, a distinct Begomovirus species with affiliation in the squash leaf curl virus cluster. Phytopathology 89:273-280.

4. Dellaporta, S. L., Wood, J., and Hicks, J. B. 1983. A plant DNA minipreparation: Version II. Plant Mol. Biol. Rep. 1:19-21.

5. Faria, J. C., Gilbertson, R. L., Hanson, S. F., Morales, F. J., Ahlquist, P., Loniello, A. O., and Maxwell, D. P. 1994. Bean golden mosaic geminivirus type II isolates from the Dominican Republic and Guatemala: Nucleotide sequences, infectious pseudorecombinants, and phylogenetic relationships. Phytopathology 84:321-329.

6. Gilbertson, R. L., Faria, J. C., Hanson, S. F., Morales, F. J., Ahlquist, P., Maxwell, D. P., and Russell, D. R. 1991. Cloning of the complete DNA genomes of four bean-infecting geminiviruses and determining their infectivity by electric discharge particle acceleration. Phytopathology 81:980-985.

7. Gilbertson, R. L., Hidayat, S. H., Paplomatas, E. J., Rojas, M. R., Hou,
Y.-M., and Maxwell, D. P. 1993. Pseudorecombination between infectious DNA components of tomato mottle and bean dwarf mosaic geminiviruses. J. Gen. Virol. 74:23-31.

8. Hanley-Bowdoin, L., Settlage, S. B., Orozco, B. M., Nagar, S., and Robertson, D. 1999. Geminiviruses: Models for plant DNA replication, transcription, and cell cycle regulation. Crit. Rev. Plant Sci. 18:71-106.

9. Idris, A. M., and Brown, J. K. 1998. Sinaloa tomato leaf curl geminivirus: Biological and molecular evidence for a new subgroup III virus. Phytopathology 88:648-657.

10. Lotrakul, P., and Valverde, R. A. 1999. Cloning of a DNA-A like genomic component of sweet potato leaf curl virus: Nucleotide sequence and phylogenetic relationships. Mol. Plant Pathol. On-line publication/1999/0206lotrakul.

11. Lotrakul, P., Valverde, R. A., Clark, C. A., Sim, J., and De La Torre, R. 1998. Detection of a geminivirus infecting sweet potato in the United States. Plant Dis. 82:1253-1257.

12. Rojas, M. R., Gilbertson, R. L., Russell, D. R., and Maxwell, D. P. 1993. Use of degenerate primers in the polymerase chain reaction to detect whitefly-transmitted geminiviruses. Plant Dis. 77:340-347.

13. Thompson, J. D., Higgins, D. G., and Gibson, T. J. 1994. Clustal W: Improving the sensitivity of progressive multiple sequence alignment through sequence weighting, positions-specific gap penalties, and weight matrix choice. Nucleic Acids Res. 22:4673-4680.

14. Wyatt, S. D., and Brown, J. K. 1996. Detection of subgroup III geminivirus isolates in leaf extracts by degenerate primers and polymerase chain reaction. Phytopathology. 86:1288-1293. 